American Journal of Applied Sciences 9 (7): 1071-1078, 2012

ISSN 1546-9239

(C) 2012 Science Publications

\title{
Lipid Profile and Antioxidant Enzymes in Normal and Stressed Rat Fed with Palm Olein
}

\author{
${ }^{1}$ Eqbal M.A. Dauqan, ${ }^{2}$ Aminah Abdullah and ${ }^{1}$ Halimah Abdullah Sani \\ ${ }^{1}$ School of Biosciences and Biotechnology, \\ ${ }^{2}$ School of Chemical Sciences and Food Technology, \\ Faculty of Science and Technology, \\ Universiti Kebangsaan Malaysia, Bangi Selangor, Malaysia
}

\begin{abstract}
Problem statement: The objective of the study was to evaluate the effect of Red Palm Olein (RPO) and Palm Olein (PO) on lipid profile and antioxidant enzyme in normal and stressed rat. Approach: Thirty six Sprague Dawley male rats which were randomly divided into six groups of 6 rats per group (tree normal groups and three stressed groups) were treated with 15\% of RPO and PO for four weeks. Results: The results at 4 weeks of treatment showed a decline in Low Density Lipoprotein Cholesterol (LDL-C) level at RPO and PO for normal and stressed groups compared to the control group. The High Density Lipoprotein Cholesterol (HDL-C) level increased in RPO and PO of the normal and stressed groups. There was significant decreased $(p \leq 0.05)$ in the TC in RPO normal group for 4 weeks of treatment compared to the control group while the TC in PO was within the normal range and increased in stressed group. After 4 weeks of treatment the study indicated that there was no significant ( $\geq \geq 0.05)$ effect on antioxidant enzyme (superoxide dismutase) in stressed rat liver but there was a significant decreased $(\mathrm{p} \leq 0.05)$ on catalase in stressed rat liver. Conclusion: These results could be due to the high content of vitamin $\mathrm{E}$ (tocopherols and tocotrienols) and $\beta$-carotene in red palm olein.
\end{abstract}

Key words: Red Palm Olein (RPO), Low Density Lipoprotein Cholesterol (LDL-C), Atherosclerotic Heart Disease (AHD), Palm Olein (PO), Total Cholesterol (TC), Glutamate Oxaloacetate Transaminase (GOT), Glutamate Pyruvate Transaminase (GPT)

\section{INTRODUCTION}

Psychological atherosclerotic lipid profile with oxidation of lipids. This turn plays a significant role in the development of Atherosclerotic Heart Disease (AHD) (Benson and Devi, 2009). Vitamin E, a naturally occurring antioxidant, is found in abundance in the environment. It is an essential fat-soluble vitamin and is considered a generic name describing bioactivities of two of its derivatives, tocopherol and tocotrienol. Tocopherol has a saturated hydrocarbon side chain whereas tocotrienol possesses three unsaturated carbon chains. The biological activity of vitamin $\mathrm{E}$ is believed to be due to its antioxidant action to inhibit lipid peroxidation in biological membranes by scavenging the peroxyl chain reaction (Azlina et al., 2005; Dauqan et al., 2011). Vitamin $\mathrm{E}$ is known to have scavenger effect on reactive oxygen species and a stabilizing effect on damaged cell membrane (Azlina $e t$ al., 2005; Dauqan et al., 2011).

The exposure to stress situations can stimulate numerous pathways, leading to increased production of oxygen free radicals Free radicals generate a cascade producing lipid peroxidation. Lipid peroxidation is one of the main events induced by oxidative stress. Lipid peroxidation can produce a range of enzymatically damaging consequences Extensive lipid peroxidation is shown to cause membrane disorganization, by peroxidizing mainly the polyunsaturated fatty acids and phospholipids leading to alterations in the ratio of polyunsaturated fatty acids to other fatty acids. Thus, lipid peroxidation is considered as a serious consequence of free radical toxicity leading to profound changes in the membrane structure and function that may even cause cellular death (Nayanatara et al., 2005). Previous studies have indicated that stress stimulated numerous pathways leading to increased levels of free radicals (Liu et al., 1996; Kashif et al., 2003; 2004; Akpinar et al., 2008). Toxic free radicals have been implicated as important pathologic factors in cardiovascular diseases. Oxidative stress arises when the balance between pro-oxidants and antioxidants is shifted toward the pro-oxidants (Torres et al., 2004).

A stressful condition leads to the excessive production of free radicals which results in oxidative stress an imbalance in the oxidant per antioxidant

Corresponding Author: Eqbal M.A. Dauqan, School of Biosciences and Biotechnology, Faculty of Science and Technology, Universiti Kebangsaan Malaysia, 43600 Bangi Selangor, Malaysia 
system. Generation of free radicals is an integral feature of normal cellular functions in contrast to excessive generation and/or inadequate removal of free radical results in destructive and irreversible damage to the cell (Srikumar et al., 2007). Under normal conditions, there is a natural defense system provided by several enzymes such as Superoxide Dismutase (SOD), Catalase (CAT) and Glutathione Peroxidase (GSH-Px) which performs a vital role for detoxification of free radicals. The use of antioxidant rich food or antioxidant food supplements became immensely popular since many diseases have been associated with oxidative stress (Akpinar et al., 2008). Therefore the objective of this research was to investigate the effect of Red Palm Olein (RPO) and Palm Oil (PO) on lipid profile and antioxidant enzyme in normal and stressed rat after 4 weeks of treatment.

\section{MATERIALS AND METHODS}

Instruments: The following instruments were used in this study: (i) High-speed homogenizer (DI18 basic, IKA, Germany) (ii) centrifuge (Eppendorf 5810 R, Germany) (iii) UV-Visible spectrophotometer (Hitachj U-1800 single, Germany), (iv) A Reflotron (ROCHE, 10007908, Germany), (v) A centrifuge (KUBOTA 2010, Malaysia) with speed 3000 r.p.m at room temperature for $10 \mathrm{~min}$.

Chemicals: Sodium hydrogen phosphate $\left(\mathrm{Na}_{2} \mathrm{HPO}_{4}\right)$, potassium dihydrogen phosphate $\left(\mathrm{KH}_{2} \mathrm{PO}_{4}\right)$, EDTA (Ethylenediaminetetraacetic acid), sodium carbonate $\left(\mathrm{Na}_{2} \mathrm{CO}_{3}\right)$, anhydrouse copper sulphate $\left(\mathrm{CuSO}_{4} 5 \mathrm{H}_{2} \mathrm{O}\right)$, Folin reagent were obtained from Sigma (USA). Hydrogen pyroxide $\left(\mathrm{H}_{2} \mathrm{O}_{2}\right)$, sodium potassium tartrate, $\mathrm{NaOH}$, cacodylic acid $\left(\left(\mathrm{CH}_{3}\right)_{2} \mathrm{AsO}_{2} \mathrm{H}\right)$ and Pyrogallol $\left(\mathrm{C}_{6} \mathrm{H}_{6} \mathrm{O}_{3}\right)$ were from Merck (Germany).

Experimental diets: The Evaluated Red Palm Olein (RPO) samples consist of carotenes (576 ppm), vitamin $\mathrm{E}(>800 \mathrm{ppm})$ and free fatty acids $(0.045 \%)$ provided by Carotino SDN BHD company and Palm Olein (PO) (Seri Murni) was obtained commercially. The test diet was prepared by mixing RPO with normal commercial rat pellet to contain $15 \%$ of the Red Palm Olein (RPO) and Palm Olein (PO). The $15 \%$ diet was prepared by adding $15 \mathrm{~g} \mathrm{RPO}$ and PO to $85 \mathrm{~g}$ rat pellet and mixed manually and the diets were then left to absorb the oils at room temperature overnight and stored at $20^{\circ} \mathrm{C}$ before the feeding trial was conducted.

Animals: Thirty six Sprague Dawley male rats each weighing between $175-240 \mathrm{~g}$ and approximately 80 days old were obtained from the animal house of the Faculty of Science and Technology, Universiti Kebangsaan Malaysia. They were randomly divided into six groups of 6 rats per group and were treated with $15 \%$ of RPO and PO for 4 weeks. Rats in control group were given normal rat pellet only while in treated groups were fed ad libitum with $15 \%$ of additional RPO and PO were given. At the end of the experiment, after 4 weeks of treatment the feeding of rats was stopped and the rats were fasted for $18 \mathrm{~h}$. They were anesthetized usinsg chloroform. Blood samples were collected from post vena cava and transferred into EDTA tubes immediately and the liver was removed immediately and was washed it with $\mathrm{NaCl}$ solution. It was stored at $-80^{\circ} \mathrm{C}$ until analyzed.

Experimental conditions: Normal (N) group: Rats were maintained under standard laboratory conditions and fed with respective diet till the completion of the experiment. For Stress (S) group rats were restrained by placing them in individual nylon plastic bag for $3 \mathrm{~h} /$ day for one week before killing. Under these conditions rat were fed with respective diet, till the completion of the experiment.

Lipid analysis of the blood: Total Cholesterol (TC) and Triglyceride (TG) were measured by strips with reflotron-machine using $32 \mu \mathrm{L}^{-1}$ whole blood. High Density Lipoprotein Cholesterol (HDL-C) was determined by strips (Roche, Germany) with reflotronmachine using $32 \mu \mathrm{L}^{-1}$ plasma blood. Plasma blood was prepared using a centrifuge (KUBOTA 2010, Malaysia) with speed 3000 r.p.m at room temperature for $10 \mathrm{~min}$ to remove red blood cells and recover plasma. Low Density Lipoprotein Cholesterol (LDL-C) was calculated from TC, HDL-C and TG values using the Friedwald equation.

LDL $(\mathrm{mg} / \mathrm{dL})=$ Total Cholesterol-HDL Cholesterol-Triglycerides/5 (Puavilai and Laoragpongse, 2004). All analyses were completed within $24 \mathrm{~h}$ of sample collection.

Determination of Catalase (CAT) activity: Enzyme activity of catalase (EC.1.11.1.6) was determined based on Aebi's method (1984). Catalase activity was measured at $22^{\circ} \mathrm{C}$ by monitoring the decomposition of hydrogen peroxide. The reaction mixture consisted of $2.0 \mathrm{~mL}$ of the liver homogenate suspended in phosphate buffer (50 mM, pH 7.0) and $1.0 \mathrm{Ml}^{-1}$ of hydrogen peroxide solution $(30 \mathrm{mM})$. The absorbance was recorded for $2 \mathrm{~m}$. at $240 \mathrm{~nm}$ immediately after adding hydrogen peroxide solution. Catalase activity was expressed as moles of hydrogen peroxide $\mathrm{reduced} / \mathrm{min} / \mathrm{mg}$ protein. 


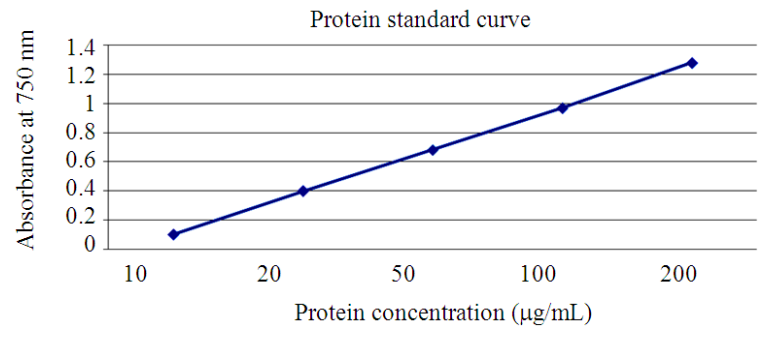

Fig. 1: Protein standard curve

Determination of Superoxide Dismutase (SOD) activity: Activity superoxide dismutase (EC.1.6.4.2) was assayed based on the method of Marklund and Marklund (1974). Superoxide dismutase activity was determined at $22^{\circ} \mathrm{C}$ by using the pyrogallol. The reaction mixture consisted of $50 \mathrm{mM}$ of cacodylic acid buffer $\mathrm{pH} 8.2$, containing $1 \mathrm{mM}$ EDTA, $300 \mu \mathrm{L}^{-1}$ of liver homogenate, $300 \mu \mathrm{L}^{-1}$ of $0.2 \mathrm{mM}$ pyrogallol. The absorbance was recorded for 3 minutes at $420 \mathrm{~nm}$ immediately after adding the pyrogallol solution. Superoxide dismutase activity was expressed as units of $\mathrm{SOD} /$ minute/mg protein.

Determination of protein concentrations: Protein concentrations were determined based on the Lowry method of Waterborg (2002). To $0.1 \mathrm{~mL}^{-1}$ of sample or standard was added $0.1 \mathrm{~mL}^{-1}$ of $2 \mathrm{~N} \mathrm{NaOH}$ and hydrolyze at $100^{\circ} \mathrm{C}$ for $10 \mathrm{~min}$ in a heating block or boiling water bath. The hydrolysate was cooled to room temperature and added $1 \mathrm{~mL}$ of freshly mixed complexforming reagent. Let the solution stand at room temperature for $10 \mathrm{~min}$. After that, $0.1 \mathrm{~mL}$ of Folin reagent was added using a vortex mixer and let the mixture stand at room temperature for 30-60 min (do not exceed $60 \mathrm{~min}$ ). The absorbance was recorded at $750 \mathrm{~nm}$ if the protein concentration was below $500 \mu \mathrm{g}$ $\mathrm{mL}^{-1}$ or at $550 \mathrm{~nm}$ if the protein concentration was between 100 and $2000 \mu \mathrm{g} \mathrm{mL}^{-1}$. Figure 1 showed the standard curve of absorbance which was plotted as a function of initial protein concentration and used it to determine the unknown protein concentrations.

Statistical analysis: Results were expressed as mean values $\pm \operatorname{SEM}(n=6)$. Means of six samples were compared by Analysis Of Variance (ANOVA). Significant differences between means were determined by Tukey's least different significant difference $(\mathrm{p} \leq 0.05)$. The software used was MINITAB ${ }^{\circledR}(14.20)$.

\section{RESULTS}

Effect of RPO and PO on blood lipid profile: Figure 2 shows the results of TC, TG, HDL-C and LDL-C levels in blood samples of normal and stressed rats that were treated with $15 \%$ of RPO and PO for 4 weeks of treatment. After 4 weeks, there was no significant difference $(\mathrm{p} \geq 0.05)$ in TC level between control group and $15 \%$ RPO and PO of normal group but there was a significant increased $(\mathrm{p} \leq 0.05)$ in $15 \%$ PO stressed group compared to $\mathrm{PO}$ and control stressed group. This could be due to the fact that RPO is rich in antioxidant particularly $\beta$-carotene and vitamin E. The results of TG level in blood samples of normal and stressed rats that were no significant difference $(\mathrm{p} \geq 0.05)$ between control group and 15\% RPO and PO of normal and stressed groups. The HDL-C level in blood samples of normal and stressed rats was significant difference $(p \leq 0.05)$ between control group and $15 \%$ RPO and PO normal groups while there was no significant difference $(\mathrm{p} \geq 0.05)$ between control group and 15\% RPO and PO stressed groups. The results of LDL-C level in blood samples of normal and stressed rats that were treated with $15 \%$ of RPO and PO for 4 weeks of treatment showed there was no significant difference $(\mathrm{p} \geq 0.05)$ between control group and $15 \%$ RPO and PO normal groups but there was significant difference $(\mathrm{p} \leq 0.05)$ between control group and $15 \%$ RPO and PO stressed groups.

Figure 3 shows the results of GOT and GPT level in blood samples of normal and stressed rats that were treated with $15 \%$ of RPO and PO for 4 weeks of treatment. After 4 weeks, there was no significant difference $(\mathrm{p} \geq 0.05)$ in GOT level between control group and 15\% RPO normal group whereas there was significant difference $(\mathrm{p} \leq 0.05)$ between control group and $15 \%$ PO normal group. The GOT level was significantly lower $(\mathrm{p} \leq 0.05)$ in $15 \% \mathrm{RPO}$ and PO stressed groups than the control group. The results of GPT level were significantly lower $(\mathrm{p} \leq 0.05)$ GPT level in 15\% RPO and PO of normal and stressed groups than the control group.

Effect of RPO and PO on liver antioxidant enzymes: Figure 4 shows the results of CAT and SOD activity in liver samples of normal and stressed rats that were treated with $15 \%$ of RPO and PO for 4 weeks of treatment. After 4 weeks, there was no significant difference $(\mathrm{p} \geq 0.05)$ in CAT activity between control group and 15\% RPO and PO normal groups. There was a significant decreased $(\mathrm{p} \leq 0.05)$ in CAT of control group and 15\% RPO stressed group but CAT was significantly higher $(\mathrm{p} \leq 0.05)$ in $15 \%$ PO stressed group than the control group. 


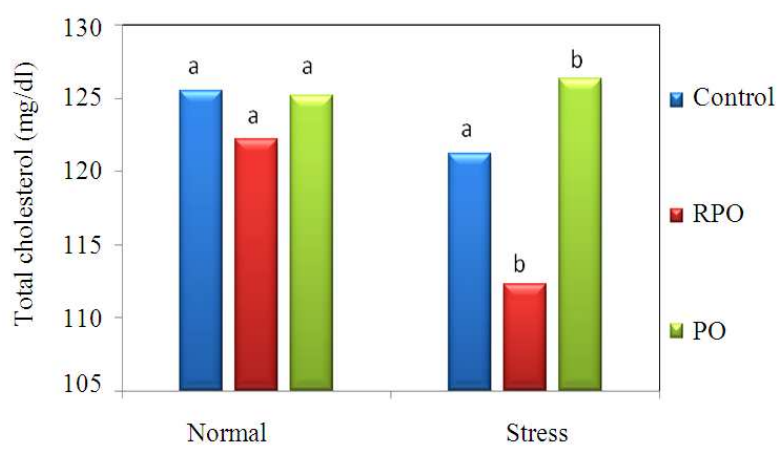

(a)

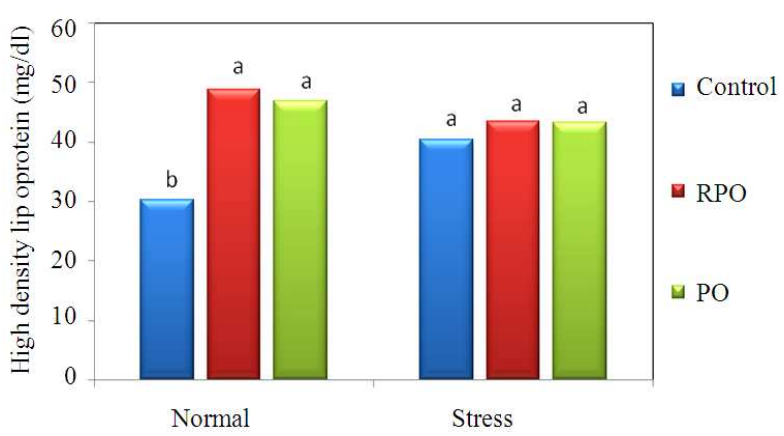

(c)

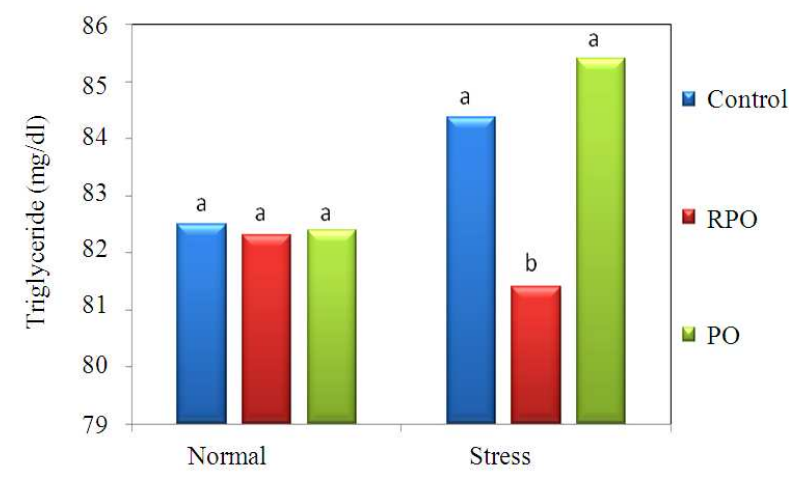

(b)

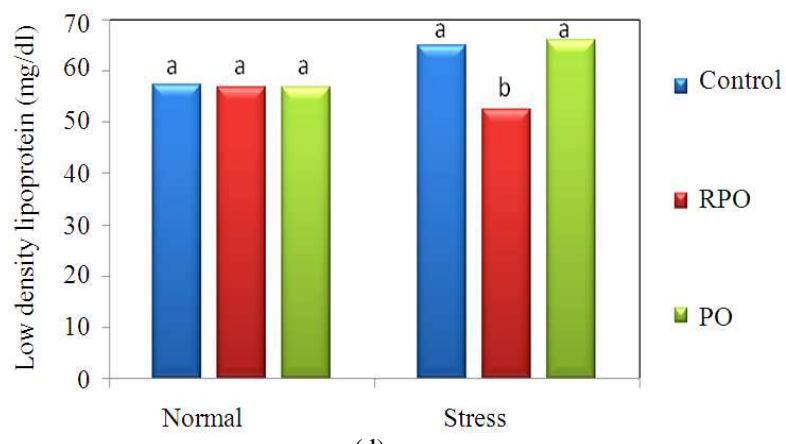

(d)

Fig. 2:(A) The Total Cholesterol (TC) in normal and stressed rats fed with red palm olein and palm olein for 4 weeks. Bars are mean \pm SEM $(n=6)$, different alphabet an each bar indicate significant different $(p \leq 0.05)$. (B) The Triglyceride (TG) in normal and stressed rats fed with red palm olein and palm olein for 4 weeks. Bars are mean \pm SEM $(n=6)$, different alphabet an each bar indicate significant different $(p \leq 0.05)$. (C) The High Density Lipoprotein (HDL-C) in normal and stressed rats fed with red palm olein and palm olein for 4 weeks. Bars are mean \pm SEM $(n=6)$, different alphabet an each bar indicate significant different $(p \leq 0.05)$. (D) The Low Density Lipoprotein (LDL-C) in normal and stressed rats fed with red palm olein and palm olein for 4 weeks. Bars are mean $\pm \operatorname{SEM}(n=6)$, different alphabet an each bar indicate significant different $(\mathrm{p} \leq 0.05)$

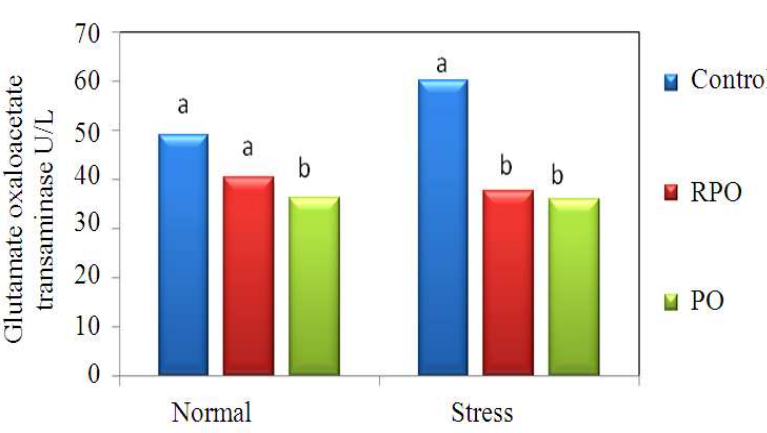

(a)

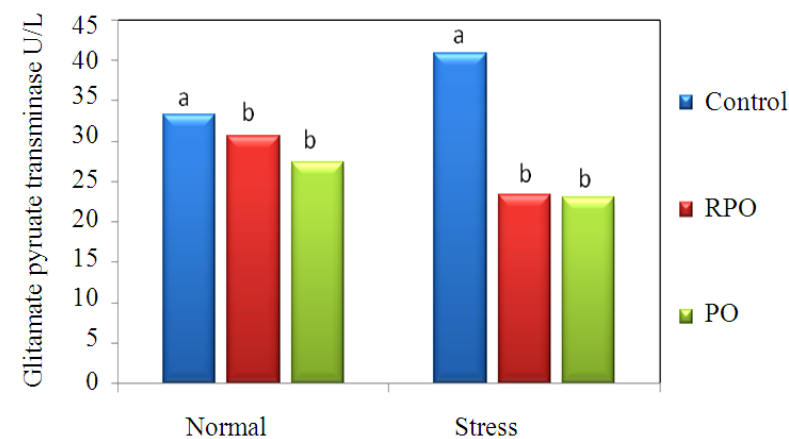

(b)

Fig. 3: (A) The Glutamate Oxaloacetate Transaminase (GOT) in normal and stressed rats fed with red palm olein and palm olein for 4 weeks. Bars are mean \pm SEM $(n=6)$, different alphabet an each bar indicate significant different $(\mathrm{p} \leq 0.05)$. (B) The Glutamate Pyruvate Transaminase (GPT) in normal and stressed rats fed with red palm olein and palm olein for 4 weeks. Bars are mean \pm SEM $(n=6)$, different alphabet an each bar indicate significant different $(\mathrm{p} \leq 0.05)$ 


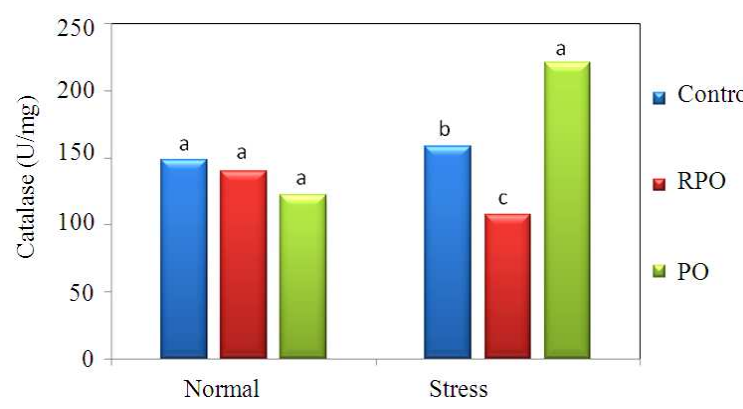

(a)

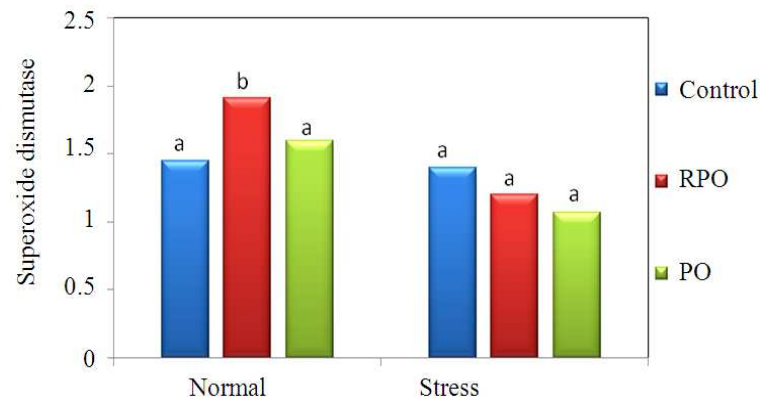

(b)

Fig. 4:(A) The catalase (CAT) activity in normal and stressed rats fed with red palm olein and palm olein for 4 weeks. Bars are mean \pm SEM $(n=6)$, different alphabet an each bar indicate significant different $(p \leq 0.05)$. (B) The Superoxide Dismutase (SOD) in normal and stressed rats fed with red palm olein and palm olein for 4 weeks. Bars are mean $\pm \operatorname{SEM}(n=6)$, different alphabet an each bar indicate significant different $(\mathrm{p} \leq 0.05)$

The results of SOD activity in liver samples were significantly lower $(\mathrm{p} \leq 0.05)$ SOD in $15 \% \mathrm{RPO}$ and PO of normal and stressed groups than the control group.

\section{DISCUSSION}

Nowadays, people cannot escape from a busy and complex lifestyle. Society should also be aware that they are often faced with the daily problems that can lead to stressful situations if they do not deal with a clever way. Stress or in everyday language is called pressure, is a common phenomenon that is often experienced by individuals in their daily lives. Among the conditions that can lead to stress conditions is a heavy workload, conflicts in relationships, serious financial problems and so on (Azlina et al., 2011). Stress is known to bring negative impact on the mind and body. Exposure to repeated or prolonged stress can lead to excessive exposure to stress hormone that increases the risk of various health problems (Kelly et al., 2008).

The antioxidant defense systems in the body can only protect the body when the amount of the free radicals is within the normal physiological level. But when this balance is shifted towards more of free radicals increasing their burden in the body either due to environmental condition or produced within the body and it leads to oxidative stress which may result in tissue injury and subsequent diseases (Aher et al., 2011). Table 1 showed the effect of different RPO and PO on body weight of normal and stressed rats. The body weight increased in each group compared with control groups. The means that the increased in body weight of rats could be attributed to the high total body fat content in the groups fed with different concentrations of RPO in comparison with control groups. Current study observed that the results of the body weight of normal rat increased more than stressed rats during the period of treatment and this indicates that stress leads to lower body weight.
Table 1: The mean \pm SEM values of body weight $(n=6)$

\begin{tabular}{lllll}
\hline & Normal rats & & Stressed rats & \\
& ------------------------ & ------------------ \\
Groups & $\begin{array}{l}\text { Body weight } \\
\text { before treatment }\end{array}$ & $\begin{array}{l}\text { Body weight } \\
\text { after treatment }\end{array}$ & $\begin{array}{l}\text { Body weight } \\
\text { before treatment }\end{array}$ & $\begin{array}{l}\text { Body weight } \\
\text { after treatment }\end{array}$ \\
\hline Control & $219.6 \pm 6.15 \mathrm{~b}$ & $329.4 \pm 9.9 \mathrm{a}$ & $204.9 \pm 8.43 \mathrm{~b}$ & $261.1 \pm 27.5 \mathrm{a}$ \\
RPO & $212 \pm 6.14 \mathrm{~b}$ & $310.1 \pm 11.3 \mathrm{a}$ & $208.6 \pm 6.06 \mathrm{~b}$ & $286.7 \pm 24.1 \mathrm{a}$ \\
PO & $211 \pm 4.66 \mathrm{~b}$ & $317.5 \pm 5.18 \mathrm{a}$ & $204.6 \pm 7.15 \mathrm{~b}$ & $306.8 \pm 5.3 \mathrm{a}$ \\
\hline
\end{tabular}

Coronary Artery Disease (CAD) is the most common form of heart disease. Fatty deposits called plaques, composed of cholesterol and fats, build upon the inner wall of the arteries. The rupture of these lipid-laden plaques and exposure of substances that promote platelet activation and thrombin generation result in thrombus, which interrupts blood flow. This condition leads to an imbalance between oxygen supply and demand and if this imbalance exceeds, it results in Myocardial Infarction (MI) or heart attack (Surekha et al., 2007).

Blood lipids as a whole participate as a key intermediate in atherogenesis (Aruj et al., 1994). Results of this study showed an increased level of TC in rat fed with PO stressed group. The treated groups under stress conditions showed a rise in the level of TC in PO group, but did not increase the level of cholesterol in the red palm oil stressed group. This finding were similar to that of Benson and Devi (2009) who reported that the TC levels has not shown significant decrease under stress conditions. The reason is that red palm oil is rich in vitamin $\mathrm{E}$ and betacarotene, while palm oil contains vitamin $\mathrm{E}$. There are many studies on the role of oxidative stress but these studies were in the etiology of type 2 diabetes, gastric, brain lipid peroxidation or DNA damage while there are very few oxidative stress studies in blood lipid profile and not under the same conditions of the current study.

The replacement of saturated fatty acids with Polyunsaturated Fatty Acids (PUFA) has been 
recommended over the last few years as dietary change that would lower serum cholesterol and assist in preventing the development of atherosclerosis. However, inclusion of PUFA in the diet increases the risk for lipid oxidation and causes oxidative damage through free radical chain reaction in cellular and subcellular membranes. Vitamin E a fat-soluble vitamin is a major antioxidant responsible for terminating free radical chain reactions that result from the oxidation of PUFA (Shireen et al., 2008). The ROS thus produced can then attack the double bonds in polyunsaturated fatty acids, inducing lipid peroxidation which may result in more oxidative cellular damage to the membrane lipids, Feeding experiments using various animal models have highlighted that red palm oil is beneficial to health by reducing oxidative stress (Oguntibeju et al., 2010). Palm oil is rich in monounsaturated fatty acids, antioxidant and vitamins and is widely used as oil in diet in many parts of the world. PO has been reported to have beneficial effects in oxidative stress association and arterial thrombosis and hypertension (Karaji-Bani et al., 2006). Red palm oil contains equal proportion of saturated and unsaturated fatty acids such as oleic acid, linolenic acid, palmitic acid, linoleic acid, stearic acid and arachidic acid. It is known to be the richest source of carotenoids in terms of provitamin A equivalents that is $\alpha$ and $\beta$ carotenes (Oguntibeju et al., 2010).

Abdel-Rahman (2011) showed that supplementation of vitamin E for 3 weeks improved the picture of oxidative stress in diabetic rats as evidenced by a significant $(\mathrm{p}<0.05)$ reduction in triglycerides and in LDL cholesterol and significant increase in HDL cholesterol. Antioxidant vitamins $\mathrm{C}$ and $\mathrm{E}$ and betacarotene have the potential to prevent or retard atherogenesis by inhibiting oxidation of Low-Density Lipoprotein (LDL) cholesterol (Singh et al., 1995). Vitamin E is considered as the standard antioxidant to which other compounds with antioxidant activities are compared, especially interms of its biological activity and clinical relevance. A part from these carotenoids such as beta-carotene (Aher et al., 2011). Duthie and Bellizzi (1999) reported that oxidation of LDL is an important event in the development of vascular disease and that antioxidants which inhibit LDL oxidation can prevent or inhibit disease progression.

The activities of Glutamate Oxaloacetate Transaminase (GOT) and Glutamate Pyruvate Transaminase (GPT) are cytosolic marker enzymes reflecting hepatocellular necrosis as they are released into the blood after cell membrane damage. Ji et al. (2006) reported that the activities of GOT and GPT in the circulation as indicators of liver damage. The effect of oxidative restraint stress on GOT and GPT results in this study was not in agreement with Devaki et al. (2010) who found that GPT and GOT increased. Devaki's study differed from this study in type of feeding which was standard rat chow and tap water ad libitum. Devaki et al. (2010) used male Wistar rats. Ji et al. (2006) reported that the enzyme activities of GOT, GPT and LDH of diabetic rats were also decreased in diabetic rats treated with four different plant extracts.

The finding of this study were similar to that of Benson and Devi (2009) who reported that the CAT activity in RPO group has shown significant decrease compared to PO and RPO groups under stress conditions. Many studies emphasize the important role of Reactive Oxygen Species (ROS) in the pathogenesis of various liver diseases (Percival, 1998; Tanikawa and Torimura, 2006; Bekheet et al., 2009). Stress is known to increase oxidative stress in the major organs including the liver (Azlina et al., 2011). Vitamin E is a major antioxidant vitamins found in the cell and can prevent cell damage through its activity as a free radical chain breaker (Aher et al., 2011). Free radicals have been implicated in the etiology of large number of major diseases. They can adversely alter many crucial biological molecules leading to loss of form and function. Such undesirable changes in the body can lead to diseased conditions. Antioxidants can protect against the damage induced by free radicals acting at various levels (Aher et al., 2011). $\beta$-Carotene has received considerable attention in recent times as a putative chain-breaking biological antioxidant and its ability to interact with free radicals such as peroxyl radicals and to scavenge and quench singlet oxygen is well documented (Farombi and Britton, 1999). Defense mechanisms against free radical-induced oxidative damage include the catalytic removal of free radicals and reactive species by factors such as Catalase (CAT), Superoxide Dismutase (SOD) and reduction of free radicals by electron donors such as vitamin $E$ (tocopherol and tocotrienol) (Limon-Pacheco and Gonsebatt, 2009).

\section{CONCLUSION}

The Total Cholesterol (TC) and Triglyceride (TG) were within the normal range with RPO and PO normal rat for duration of treatment while under stress condition the PO group has shown increase in TC level compared to RPO and control groups. However, the HDL-C increased in RPO and PO of normal group but it was within normal range under stress condition. In contrast, the results of LDL-C decreased with RPO and 
PO of stressed group compared to the control group. However, rats treated with 15\% RPO and PO for 4 weeks showed a decreased in GOT and GPT under normal and stress condition. These results could be due to the high content of vitamin $\mathrm{E}$ (tocopherols and tocotrienols) and $\beta$-carotene in red palm olein. Treatment with $15 \%$ RPO and PO diets did not affect the CAT level after 4 weeks of treatment under normal condition while there was decreased in CAT level with RPO and increased with PO under stress conditions. Additionally, the results in RPO group showed that higher SOD activity compared to PO and control groups under normal conditions while there were no significant difference $(\mathrm{p} \leq 0.05)$ in SOD between the control group and treated groups under stress conditions.

\section{ACKNOWLEDGEMENT}

This study was supported by the Organization for Women in Science for the Developing World (OWSDW) and the research was funded by UKMGUP-NBT-27-103, UKM-HEJIM-Industri-16-2010 and UKM OUP-NBT-29-139/2011. We grateful thank to caroteno sdn bhd Malaysia for providing red palm olein sample.

\section{REFERENCES}

Abdel-Rahman, Z., 2011. The effects of antioxidants supplementation on haemostatic parameters and lipid profiles in diabetic rats. J. Am. Sci., 7: 835840.

Aher, V.D., A. Wahi, A.M. Pawdey and A. Sonawane, 2011. Antioxidants as immunomodulator: An expanding research avenue. Int. J. Curr. Pharm. Res., 3: 8-10.

Akpinar, D., P. Yargicoglu, N. Derin, Y. Aliciguzel and A. Agar, 2008. The effect of lipoic acid on antioxidant status and lipid peroxidation in rats exposed to chronic restraint stress. Physiol. Res., 57: 893-901. PMID: 18052687

Aruj, N., T. Sharafatullah, R. Najam, S.P. Ahmed and S.I. Ahmad, 1994. Biochemical alterations during swimming induced stress. Pak. J. Pharm. Sci., 7: 25-33. PMID: 16414753

Azlina, M.F., M.I. Nafeeza and B.A. Khalid, 2005. A comparison between tocopherol and tocotrienol effects on gastric parameters in rats exposed to stress. Asia Pac. J. Clin. Nutr., 14: 358-365. PMID: 16326642
Azlina, N., M. Fahmi and T. Muharani, 2011. Effects of tocotrienol and tocopherol supplementation on liver oxidative status and antioxidant enzyme activity in stress-induced rats. Sains Malaysiana, 40: 481-487.

Bekheet, I.W., M.E. Madkour, N.A. Ghaffar, M.M.F. Nosseir and M.M. Moussa et al., 2009. The role of myeloperoxidase in hepatitis $\mathrm{C}$ virus infection and associated. Open Tropical Med. J., 2: 1-7.

Benson, M.K. and K. Devi, 2009. Influence of $\omega-6 / \omega-3$ rich dietary oils on lipid profile and antioxidant enzymes in normal and stressed rats. Indian J. Exp. Biol., 47: 98-103. PMID: 19374164

Dauqan, E., H.A. Sani, A. Abdullah and Z.M. Kasim, 2011. Effect of different vegetable oils (red palm olein, palm olein, corn oil and coconut oil) on lipid profile in rat. Food Nutr. Sci., 2: 253-258. DOI: 10.4236/fns.2011.24036

Devaki, M., R. Nirupama and H.N. Yajurvedi, 2010. Repeated acute stress alters activity of serum aminotransferases and lactate dehydrogenase in rat. JPBS, 23: 1-4.

Duthie, G.G. and M.C. Bellizzi, 1999. Effects of antioxidants on vascular health. Br. Med. Bull., 55: 568-577.

Farombi, E.O. and G. Britton, 1999. Antioxidant activity of palm oil carotenes in organic solution: Effects of structure and chemical reactivity. Food Chem., 64: 315-321. DOI: 10.1016/S03088146(98)00108-3

Ji, Q., Z.X. Luo, C.X. Yuan and A.R. Tabrum, 2006. A swimming mammaliaform from the middle jurassic and ecomorphological diversification of early mammals. Science, 311: 1123-1127. DOI: 10.1126/science. 1123026

Karaji-Bani, M., F. Montazeri and M. Hashemi, 2006. Effect of palm oil on serum lipid profile in rats. Pak. J. Nutr., 5: 234-236.

Kashif, S.M., R. Zaidi and N. Banu, 2004. The antioxidant potential of vitamins $\mathrm{A}, \mathrm{E}$ and $\mathrm{C}$ in modulating oxidative stress in rat brain. Clin.. Chim. Acta, 340: 229-233. DOI: 10.1016/J.CCCN.2003.11.003

Kashif, S.M., R. Zaidi, T.M. Al-Qirim, N. Hoda and N. Banu, 2003. Modulation of restraint stress induced oxidative changes in rats by antioxidant vitamins. J. Nutr. Biochem., 14: 633-636. DOI: 10.1016/S0955-2863(03)00117-7

Kelly, M.M., A.R. Tyrka, G.M. Anderson, L.H. Price and L.L. Carpenter, 2008. Sex differences in emotional and physiological responses to the trier social stress test. J. Behav. Therapy Exp. $\begin{array}{llll}\text { Psychiatry, } & 39: & \text { 87-98. }\end{array}$ 10.1016/j.jbtep.2007.02.003 
Limon-Pacheco, J. and M.E. Gonsebatt, 2009. The role of antioxidants and antioxidant-related enzymes in protective responses to environmentally induced oxidative stress. Mutation Res., 674: 137-147. DOI: 10.1016/J.MRGENTOX.2008.09.015

Liu, J., X. Wang, M.K. Shigenaga, H.C. Yeo and A. Mori et al., 1996. Immobilization stress causes oxidative damage to lipid, protein and DNA in the brain of rats. FASEB J., 10: 1532-1538. PMID: 8940299

Marklund, S. and G. Marklund, 1974. Involvement of the superoxide anion radical in the autoxidation of pyrogallol and a convenient assay for superoxide dismutase. Eur. J. Biochem., 47: 469-474. PMID: 4215654

Nayanatara, A.K., H.S. Nagaraja and B.K. Anupama, 2005. The effect of repeated swimming stress on organ weights and lipid peroxidation in rats. Thai J. Physiol. Sci., 18: 3-9.

Oguntibeju, O.O., A.J. Esterhuyse and E.J. Truter, 2010. The possible role of red palm oil supplementation in reducing oxidative stress in HIV/AIDS and TB patients: A review. J. Med. Plants Res., 4: 188-196.

Percival, M., 1998. Antioxidants. Advanced Nutrition Publications.

Puavilai, W. and D. Laoragpongse, 2004. Is Calculated LDL-C by using the new modified Friedewald equation better than the standard Friedewald equation? J. Med. Assoc. Thai., 87: 589-593. PMID: 15279333

Shireen, K.F., R.D. Pace, M. Mahboob and A.T. Khan, 2008. Effects of dietary vitamin E, C and soybean oil supplementation on antioxidant enzyme activities in liver and muscles of Rats. Food Chem. Toxicol., 46: 3290-3294. DOI: 10.1016/J.FCT.2008.07.015
Singh, R.B., S. Ghosh, M.A. Niaz, R. Singh and R. Beegum et al., 1995. Dietary intake, plasma levels of antioxidant vitamins and oxidative stress in relation to coronary artery disease in elderly subjects. Am. J. Cardiol., 76: 1233-1238. PMID: 7503002

Srikumar, R., N.J. Parthasarathy, S. Manikandan, G.S. Narayanan and R. Sheeladevi 2007. Effect of Triphala on oxidative stress and on cell-mediated immune response against noise stress in rats. Mol. Cell. Biochem., 283: 67-74. DOI: 10.1007/s11010-006-2271-0

Surekha, R.H., B.B. Srikanth, P. Jharna, R.V. Ramachandra and R.V. Dayasagar et al., 2007. Oxidative stress and total antioxidant status in myocardial infarction. Singapore Med. J., 48: 137142. PMID: 17304393

Tanikawa, K. and T. Torimura, 2006. Studies on oxidative stress in liver diseases: Important future trends in liver research. Med. Mol. Morphol., 39: 22-27. DOI: $10.1007 / \mathrm{s} 00795-006-0313-\mathrm{z}$

Torres, R.L., I.L. Torres, G.D. Gamaro, F.U. Fontella and P.P. Silveira et al., 2004. Lipid peroxidation and total radical-trapping potential of the lungs of rats submitted to chronic and sub-chronic stress. Braz. J. Med. Biol. Res., 37: 185-192. PMID: 14762572

Waterborg, J.H., 2002. The Lowry method for protein quantitation. Protein Protocols Handbook, 1: 7-9. DOI: $10.1385 / 1-59259-169-8: 7$ 